Check for updates

Cite this: Chem. Sci., 2019, 10, 2604

๑ All publication charges for this article have been paid for by the Royal Society of Chemistry

Received 30th September 2018 Accepted 24th December 2018

DOI: $10.1039 / \mathrm{c} 8 \mathrm{sc} 04350 \mathrm{~g}$

rsc.li/chemical-science

\section{Highly reversible potassium-ion intercalation in tungsten disulfide $\uparrow t$}

\author{
Ruding Zhang, (D) § Jingze Bao, § Yilong Pan and Chuan-Fu Sun (D)*
}

Rechargeable potassium-ion batteries (PIBs) show promise beyond Li-ion technology in large-scale electrical-energy storage due to the abundance and low cost of potassium resources. However, the intercalation of large-size $\mathrm{K}^{+}$generally results in irreversible structural degradation and short lifespan to the hosts, representing a major obstacle. Here, we report a new electrochemical $\mathrm{K}^{+}$-intercalation host, tungsten disulfide $\left(\mathrm{WS}_{2}\right)$, which can store $0.62 \mathrm{~K}^{+}$per formula unit with a reversible capacity of $67 \mathrm{~mA} \mathrm{~h} \mathrm{~g}^{-1}$ and well-defined voltage plateaus at an intrinsically safe average operation potential of $0.72 \mathrm{~V}$ versus $\mathrm{K} / \mathrm{K}^{+}$. In situ $\mathrm{X}$-ray diffraction and ex situ electron microscopy revealed the underlying intercalation mechanism, a relatively small cell volume change (37.81\%), and high reversibility of this new battery chemistry. Such characteristics impart $\mathrm{WS}_{2}$ with ultrahigh structural stability and a long lifespan, regardless of deep or fast charging. $W_{2}$ achieved record-high cyclability among chalcogenides up to 600 cycles with $89.2 \%$ capacity retention at $0.3 \mathrm{C}$, and over 1000 cycles with $96.3 \%$ capacity retention and an extraordinary average Coulombic efficiency of $99.90 \%$ at $2.2 \mathrm{C}$. This intercalation electrochemistry may open up new opportunities for the design of long-cycle-life and high-safety PIBs.

\section{Introduction}

Reversible electrochemical intercalation of metal ions in solids has laid the foundation for rechargeable batteries which are recognized as the key to utilization of 'clean' energy. ${ }^{1-3}$ The wellestablished lithium-ion batteries (LIBs), for instance, rely dominantly on the (de)intercalation of lithium-ions $\left(\mathrm{Li}^{+}\right)$in graphite, $\mathrm{LiCoO}_{2}$, and $\mathrm{LiFePO}_{4}$. These layered solids typically experience small volume changes upon $\mathrm{Li}^{+}$(de)insertion. Such structural stability enables the realization of the stable electrode-electrolyte interface, long-term cyclability and steady output of electrical energy. ${ }^{1-3}$ Despite these prominent virtues, the limited abundance of lithium resources $(\sim 0.0017 \mathrm{wt} \%$ in the Earth's crust) makes $\mathrm{Li}^{+}$-technology unlikely to meet the continually increasing demands for stationary storage of electric power. This limitation drives the search for cost-effective alternatives beyond $\mathrm{Li}^{+}$chemistry. ${ }^{4-7}$ Given the abundance ( 2.09 wt\%, 1000-times higher than Li) and low cost of potassium resources, potassium-ion batteries (PIBs) in principle provide tremendous potentials in grid-scale energy storage

CAS Key Laboratory of Design and Assembly of Functional Nanostructures, and Fujian Key Laboratory of Nanomaterials, Fujian Institute of Research on the Structure of Matter, Chinese Academy of Sciences, Fuzhou, Fujian, 350002, P.R. China. E-mail: cfsun@fjirsm.ac.cn

$\uparrow$ Dedicated to Prof. Jin-Shun Huang on the occasion of his 80th birthday.

\$ Electronic supplementary information (ESI) available. See DOI: $10.1039 / \mathrm{c} 8 \mathrm{sc} 04350 \mathrm{~g}$

$\S$ The authors contributed equally to this work. and have recently been receiving rapidly increasing attention. $^{5,8-21}$

$\mathrm{K}^{+}$has an ionic radius of $1.38 \AA$, which is $\sim 1.8$-times that of $\mathrm{Li}^{+}$. This larger ionic size makes $\mathrm{K}^{+}$-intercalation behavior apparently differ from its $\mathrm{Li}^{+}$counterpart, and the (de)insertion of $\mathrm{K}^{+}$often induces irreversible structural degradation and, thus, a short lifespan to the hosts. ${ }^{5,18}$ For instance, $\mathrm{K}^{+}$fails to intercalate in the crystalline $\mathrm{FePO}_{4}$ cathode, ${ }^{22}$ whereas the graphite anode is ready for $\mathrm{K}^{+}$insertion but exhibits a large volume expansion $(\sim 61 \%)$ and inferior cyclability. ${ }^{5,9,12,23}$ Therefore, the key challenge lies in the search of host materials that can reversibly intercalate $\mathrm{K}^{+}$while exhibiting high structural stability. ${ }^{5,10,18,24}$ To this end, a large number of materials, such as hard/soft carbon, ${ }^{15,25}$ organic compounds, ${ }^{26,27}$ Mxenes, ${ }^{28}$ transition metal oxides/sulfides/phosphates, ${ }^{19,29-33}$ Prussian Blue and its analogs, ${ }^{10,16,34,35}$ have been investigated intensively and show promising prospects. Among them, the Prussian Blue analogs could effectively accommodate the structural changes induced by $\mathrm{K}^{+}$(de)insertion due to a framework structure and are probably the most promising cathode materials to date..$^{\mathbf{1 0 , 1 6 , 3 4 , 3 5}}$ The currently available anode materials, however, have not yet been able to achieve overall electrochemical performances that match the Prussian Blue analogs, representing a critical issue that needs to be solved for the realization of PIBs.

Here, we report a new electrochemical $\mathrm{K}^{+}$-intercalation host: two-dimensional layered $\mathrm{WS}_{2}$. Our results showed that a maximum of $0.62 \mathrm{~K}^{+}$readily (de)intercalated in $\mathrm{WS}_{2}$, corresponding to a specific capacity of $67 \mathrm{~mA} \mathrm{~h} \mathrm{~g}{ }^{-1}$. This new intercalation chemistry exhibited well-defined voltage plateaus 
and an average operation potential of $0.72 \mathrm{~V}$ versus $\mathrm{K} / \mathrm{K}^{+}$. The former favored the steady output of cell voltage and electrical energy, whereas the latter made it intrinsically free from the potassium plating ( $0 \mathrm{~V}$ versus $\mathrm{K} / \mathrm{K}^{+}$) that may have caused catastrophic internal short-circuit. In-depth kinetic and mechanistic analyses captured $\mathrm{K}^{+}$diffusion behavior, the underlying intercalation mechanism, and high reversibility of this new battery chemistry. Upon $\mathrm{K}^{+}$intercalation, $\mathrm{WS}_{2}$ transformed to $\mathrm{K}_{0.62} \mathrm{WS}_{2}$, accompanied with cell volume expansion (37.81\%) as small as approximately one-half that of graphite. This feature enabled ultrahigh structural stability and electrochemical cyclability regardless of deep or fast charging, as shown unambiguously by $84.5 \%$ capacity retention over 100 cycles at $0.075 \mathrm{C}$ and $96.3 \%$ capacity retention over 1000 cycles at $2.2 \mathrm{C}$. Moreover, it was observed that the electrochemical $\mathrm{K}^{+}$-(de) intercalation into $\mathrm{WS}_{2}$ largely differed from that of its $\mathrm{Li}^{+} / \mathrm{Na}^{+}$ counterparts and provided far more distinct voltage plateaus, thus offering advantages beyond $\mathrm{Li} / \mathrm{Na}$-ion technologies.

\section{Results and discussion}

Hexagonal $2 \mathrm{H}-\mathrm{WS}_{2}$ exhibited a characteristic layered structure with an interlayer spacing of $6.180 \AA$ (Fig. 1A and S1, ESI $\ddagger$ ). Two adjacent layers interacted with each other through weak van der Waals interactions, which offered the possibility of introducing $\mathrm{K}^{+}$into the interlayers, which is a similar working principle to $\mathrm{Li}^{+}$intercalation into $\mathrm{TiS}_{2}$ in the first prototype rechargeable LIBs. ${ }^{1,2}$ Commercial $\mathrm{WS}_{2}$ powder was adopted directly for understanding the electrochemical $\mathrm{K}^{+}$-intercalation behavior. Scanning electron microscopy (SEM) and transmission electron microscopy (TEM) revealed that $\mathrm{WS}_{2}$ was in a plate shape with a thickness of $\sim 100-200 \mathrm{~nm}$ and a lateral size of $\sim 1-3 \mu \mathrm{m}$ (Fig. 1B, C). X-ray diffraction (XRD) patterns confirmed the $P 6_{3} /$ $m m c$ structure and the purity of the $\mathrm{WS}_{2}$ materials. The presentation of solely Bragg peaks (002), (004), (006), and (008) indicated a preferential crystallographic orientation of the powder (Fig. 1D), in agreement with the observed plate shape.

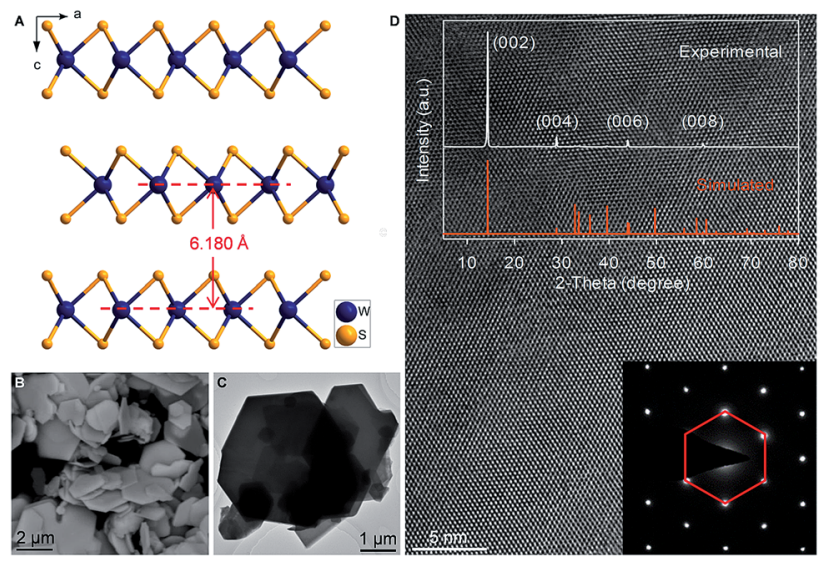

Fig. 1 Materials characterization of $W_{2}$. (A) Structural view of $W_{2}$ along the $b$-axis showing a characteristic layered structure. (B and $C$ ) SEM (B) and TEM (C) images of $W_{2}$. (D) XRD pattern, HRTEM image and corresponding EDP pattern of $\mathrm{WS}_{2}$.
High-resolution TEM and electron diffraction patterns (EDPs) further verified the hexagonal phase of $\mathrm{WS}_{2}$ (Fig. 1D).

$\mathrm{WS}_{2}$ bulk electrodes were prepared through a slurry bladecoating method. They possessed active material loading of $2.48-2.75 \mathrm{mg} \mathrm{cm}{ }^{-2}$, and a specific surface area of $14.0 \mathrm{~m}^{2} \mathrm{~g}^{-1}$ given by Brunauer-Emmett-Teller (BET) analysis (Fig. S2, ESI + ). Previously, we demonstrated that a concentrated 5 molar (5 M) electrolyte exhibits higher reduction resistance over that of a $1 \mathrm{M}$ electrolyte, and contributes better electrochemical performance for a bismuth anode. ${ }^{36}$ Therefore, $5 \mathrm{M}$ potassium bis(trifluoromethylsulfonyl)imide (KTFSI) in diethylene glycol dimethyl ether (DEGDME) was adopted as an electrolyte here. Fig. 2A presents cyclic voltammetry (CV) curves in the initial five cycles at $0.1 \mathrm{mV} \mathrm{s}^{-1}$. The cathodic peaks around 0.5 and $0.36 \mathrm{~V}$ in the initial cycle correspond to $\mathrm{K}^{+}$-intercalation in $\mathrm{WS}_{2}$ and the formation of a solid electrolyte interphase (SEI), whereas the two anodic peaks at 0.77 and $1.33 \mathrm{~V}$ relate to the deintercalation of $\mathrm{K}^{+}$. After the activation cycle, the overlap of the subsequent CV curves indicated highly reversible $\mathrm{K}^{+}$(de)intercalation chemistry. At a current density of $5 \mathrm{~mA} \mathrm{~g}^{-1}$ (rate of $\sim 0.075 \mathrm{C}$ ), $\mathrm{WS}_{2}$ delivered an initial reversible capacity of $67 \mathrm{~mA} \mathrm{~h} \mathrm{~g}^{-1}$ (or $238 \mathrm{~mA} \mathrm{~h} \mathrm{~cm}^{-3}$ ), which is comparable with that of conventional Prussian Blue analogs, and corresponds to the insertion of 0.62 $\mathrm{K}^{+}$per formula unit (Fig. 2B). An initial Coulombic efficiency (CE) of $56.6 \%$ could be mainly attributed to SEI formation, which is commonly observed in PIB anodes., ${ }^{\mathbf{9}, 12,13}$ Even under deep (de)potassiation, $\mathrm{WS}_{2}$ continued to deliver a reversible capacity of $56.6 \mathrm{~mA} \mathrm{~h} \mathrm{~g}{ }^{-1}$ after 100 cycles with a capacity retention of $84.5 \%$. The voltage profiles and differential capacity $(\mathrm{d} Q / \mathrm{d} V)$ curve at the 5 th cycle showed a main voltage plateau at
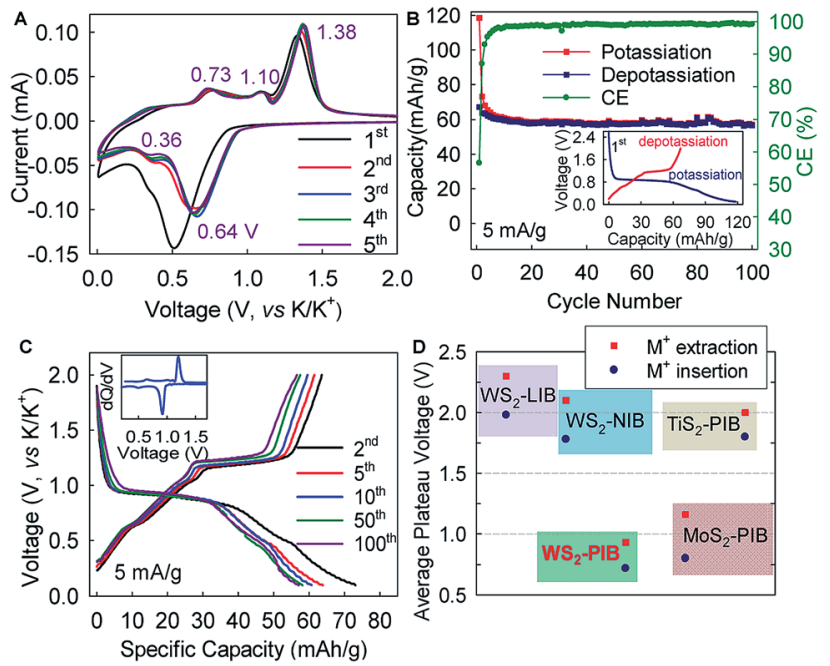

Fig. 2 Electrochemical $\mathrm{K}^{+}$(de)intercalation behavior in $\mathrm{WS}_{2}$. (A) $\mathrm{CV}$ profiles of the $\mathrm{WS}_{2}$ electrode at a scan rate of $0.1 \mathrm{mV} \mathrm{s}^{-1}$. (B) Galvanostatic cycling of the $W_{2}$ electrode at a current of $5 \mathrm{~mA} \mathrm{~g}^{-1}$. The inset shows the voltage profile of the first cycle. (C) Voltage profiles of the $\mathrm{WS}_{2}$ electrode at a current of $5 \mathrm{~mA} \mathrm{~g}^{-1}$. The inset is the corresponding $\mathrm{d} Q / \mathrm{d} V$ curve at the fifth cycle, which shows characteristic potassiation/depotassiation plateaus at $0.5 / 0.65 \mathrm{~V}$ and $0.93 / 1.2 \mathrm{~V}$. (D) Average plateau voltage of metal disulfides in LIBs, NIBs, and PIBs. The voltage gaps between $\mathrm{M}^{+}$insertion (red square) and extraction (blue dot) represent the voltage hysteresis. 

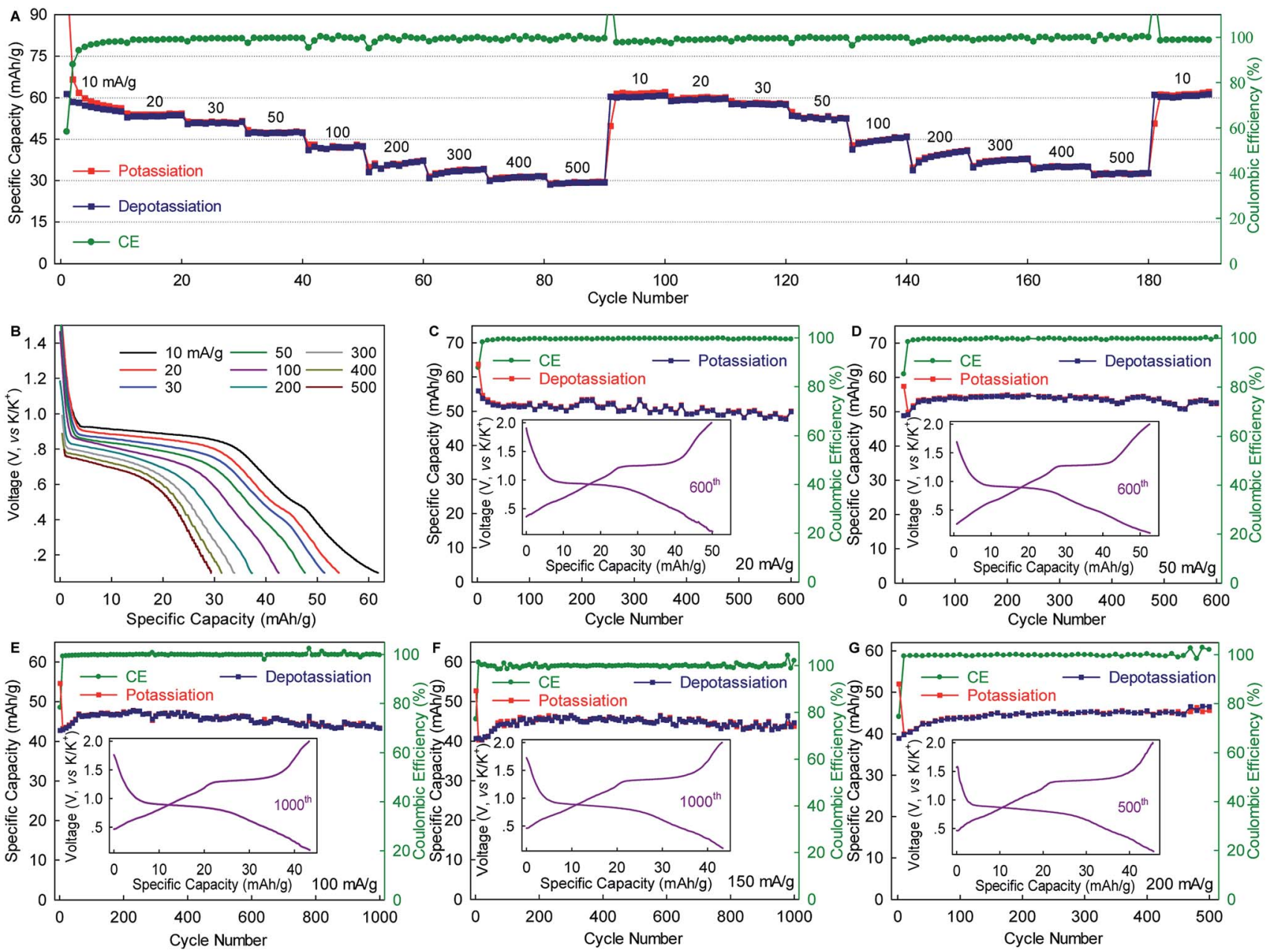

Fig. 3 Rate capability and long-term cyclability of $\mathrm{WS}_{2}$. (A) Rate capability. (B) Potassiation voltage profiles at various rates. (C-G) Long-term cyclability at various rates. All batteries were cycled once at $10 \mathrm{~mA} \mathrm{~g}^{-1}$ for activation. For clarity, those data are not shown here. Insets in $\mathrm{C}-\mathrm{G}$ show the corresponding voltage profile.

$0.93 \mathrm{~V}$ and a less evident one at $0.5 \mathrm{~V}$ upon $\mathrm{K}^{+}$insertion, as well as corresponding depotassiation plateaus at 0.65 and $1.2 \mathrm{~V}$ (Fig. 2C). The multiple voltage plateaus suggested a stepwise $\mathrm{K}^{+}$(de)insertion, and the reaction equation can be described as:

$$
\mathrm{WS}_{2}+0.62 \mathrm{~K}^{+}+0.62 \mathrm{e}^{-}=\mathrm{K}_{0.62} \mathrm{WS}_{2}
$$

The lower average operation potential $(0.72 / 0.93 \mathrm{~V})$ of the $\mathrm{WS}_{2}$ anode could provide higher energy density in full cells compared with those of $\mathrm{MoS}_{2}$ (ref. 29) and $\mathrm{TiS}_{2},{ }^{37,38}$ whereas a small potential hysteresis of $0.21 \mathrm{~V}$ (voltage gap between ion insertion and extraction) generally favors high round-trip energy efficiency (Fig. 2D). Equally important, this average potential made it intrinsically free from the potassium plating $\left(0 \mathrm{~V}, v s . \mathrm{K} / \mathrm{K}^{+}\right)$that may have caused catastrophic battery failure.

Interestingly, the electrochemical $\mathrm{K}^{+}$-(de)intercalation into $\mathrm{WS}_{2}$ differed largely from that of its $\mathrm{Li}^{+} / \mathrm{Na}^{+}$counterparts, which occurs at a plateau potential $>1.5 \mathrm{~V}$ and is typically considered to be cathode chemistry (Fig. 2D and S3, ESI+)..$^{\mathbf{3 9 4} \text { Mo }}$ Moreover, the potential plateaus in $\mathrm{a} \mathrm{K}^{+}$system are far more distinct than those in $\mathrm{Li}^{+} / \mathrm{Na}^{+}$systems, ${ }^{39-41}$ thereby offering advantages over LIBs/NIBs. In addition, $\mathrm{WS}_{2}$ exhibited a further reduction degradation potential of $\sim 0.08 \mathrm{~V}$ below which reduction of $\mathrm{WS}_{2}$ to $\mathrm{W}$ metal occurs (Fig. S4, ESI $\$$ ). This potential is $\sim 0.42 \mathrm{~V}$ lower than that of $\mathrm{MoS}_{2}$, indicating higher resistance to reduction degradation. We showed twice that a higher capacity $\left(212 \mathrm{~mA} \mathrm{~h}^{-1}\right.$ ) could be achieved with a cutoff voltage of $0 \mathrm{~V}$, but the preferred flat voltage plateaus became indistinct (Fig. S4, ESI + ). Therefore, the cutoff voltage for battery cycling was set to $0.1 \mathrm{~V}$.

The $\mathrm{WS}_{2}$ anode exhibited considerable rate capability and long-term cyclability. As shown in Fig. $3 \mathrm{~A}, \mathrm{WS}_{2}$ delivered capacity of $\sim 60, \sim 50, \sim 45$ and $\sim 40 \mathrm{~mA} \mathrm{~g}^{-1}$ at rates of 10, 50, 100 , and $200 \mathrm{~mA} \mathrm{~g}^{-1}(0.15 \mathrm{C}, 0.75 \mathrm{C}, 1.5 \mathrm{C}$, and $3 \mathrm{C})$, respectively, which correspond to $89.6 \%, 74.6 \%, 67.2 \%$, and $59.7 \%$ of the maximum capacity. Even at a rate as high as $500 \mathrm{~mA} \mathrm{~g}^{-1}$ (7.5, which corresponds to a charging time of $8 \mathrm{~min}$ ), nearly half of the maximum capacity remained achievable. Of equal importance, the reversible capacity returned to $\sim 60 \mathrm{~mA} \mathrm{~h}^{-1}$ after two repeated rate cycles, again confirming the structural stability of 

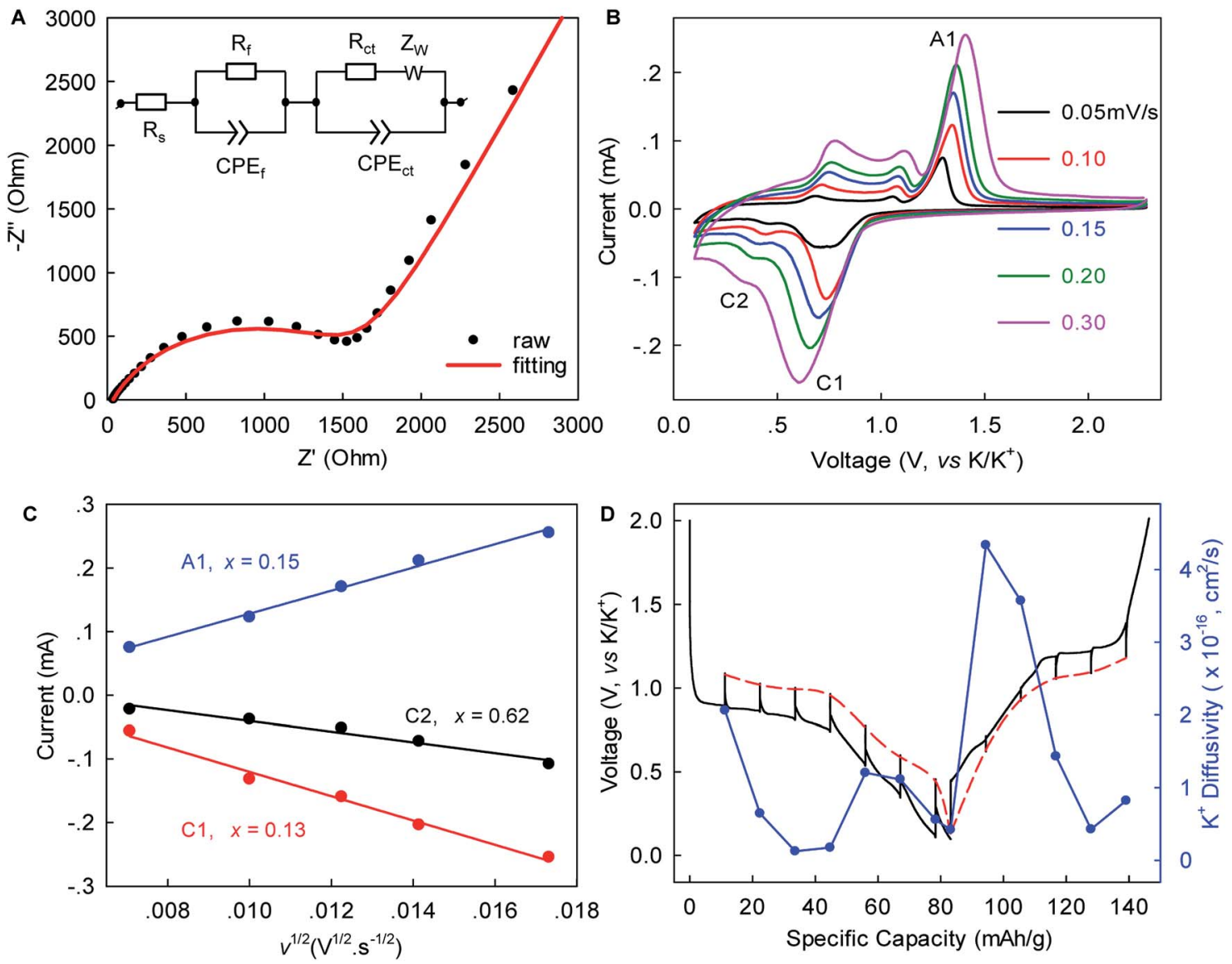

Fig. 4 Kinetic analysis of $\mathrm{K}^{+}$(de)intercalation in $\mathrm{WS}_{2}$. (A) EIS of $\mathrm{WS}_{2}$ after five (de)potassiation cycles. The inset shows the equivalent circuit for data fitting, where $R_{\mathrm{s}}, R_{\mathrm{f}}, R_{\mathrm{ct}}, \mathrm{CPE}$, and $Z_{\mathrm{w}}$ represent electrolyte resistance, contact resistance, charge-transfer resistance, constant-phase element, and Warburg ion-diffusion resistance, respectively. (B) CV profiles at various scan rates. (C) The peak currents versus the square root of the scan rate for peaks C1, C2 and A1 marked in B. (D) GITT profiles.

$\mathrm{WS}_{2}$ upon $\mathrm{K}^{+}$-(de)intercalation. Moreover, the voltage plateaus were well preserved with relatively small potential polarization even at high rates (Fig. 3B). An average potassiation plateau at $500 \mathrm{~mA} \mathrm{~g}{ }^{-1}$ was $0.68 \mathrm{~V}$, which is only $0.22 \mathrm{~V}$ lower than that at $10 \mathrm{~mA} \mathrm{~g}{ }^{-1}$. Fig. $3 \mathrm{C}-\mathrm{G}$ depict long-term cyclability. The $\mathrm{WS}_{2}$ anode achieved a capacity retention of $89.3 \%$ over 600 cycles and an average $\mathrm{CE}$ of $99.48 \%$ at $20 \mathrm{~mA} \mathrm{~g}^{-1}(\sim 0.3 \mathrm{C})$. At $50 \mathrm{~mA} \mathrm{~g}^{-1}$, the capacity retention and average CE over 600 cycles reached $96 \%$ and $99.51 \%$, respectively. Under higher rates of 100 and $150 \mathrm{~mA} \mathrm{~g}^{-1}$ (1.5C and 2.2C), remarkable capacity retentions of $90.8 \%$ and $96.3 \%$, respectively, were achieved over 1000 cycles with average CE as high as $99.80 \%$ and $99.90 \%$. This cyclability is superior to that of all the previously reported chalcogenides, and among the best reported to date for PIB anodes. ${ }^{5,29,31,32,37,38}$ Such cyclability, together with the considerable rate capability and small polarization (Fig. 3 and S5, ESI:), suggest the ultrahigh structural stability of $\mathrm{WS}_{2}$ and relatively fast $\mathrm{K}^{+}$diffusion within it.

Electrochemical impedance spectroscopy (EIS), rate-scanning CV, and galvanostatic intermittent titration technique (GITT) experiments were conducted to gain further kinetic insights into this $\mathrm{K}^{+}$-(de)intercalation chemistry. Fig. 4A and S6, ESI $\$$ show that the contact resistance $\left(R_{\mathrm{f}}\right)$ related to the ion- diffusion resistance across the SEI layer was estimated to be $31.54 \Omega$ after five-cycle activation. This small $R_{\mathrm{f}}$ suggested relatively fast $\mathrm{K}^{+}$permeation through the SEI layer, which would have been largely responsible for the excellent rate capability. The charge transfer resistance $\left(R_{\mathrm{ct}}\right)$ of $1671 \Omega$ was 1.6-times lower than that observed in graphite $(4358 \Omega),{ }^{12}$ indicating faster charge transfer in $\mathrm{WS}_{2}$. The chemical diffusion coefficient of $\mathrm{K}^{+}$within $\mathrm{WS}_{2}$ was deduced from the rate-scan CV (Fig. 4B, C) according to the Randles-Sevcik equation, ${ }^{42}$

$$
i_{\mathrm{p}}=\left(2.69 \times 10^{5}\right) n^{3 / 2} C_{0} A D^{1 / 2} \nu^{1 / 2}
$$

where $i_{\mathrm{p}}$ is the peak current; $n$ is the number of electrons transferred in the redox process (here $n=1$ ); $C_{0}$ is the $\mathrm{K}^{+}$ concentration in the electrode; $A$ represents the effective surface area (BET surface area in this case); $D$ is the diffusion coefficient of $\mathrm{K}^{+}$; and $\nu$ is the scan rate $\left(\mathrm{V} \mathrm{s}^{-1}\right)$. Two cathodic peaks around $0.70(\mathrm{C} 1)$ and $0.41 \mathrm{~V}(\mathrm{C} 2)$, as well as an anodic peak around $1.35 \mathrm{~V}$ (A1), were used for deduction of $D_{\mathrm{K} \text {-ion, }}$, where $x$ in $\mathrm{K}_{x} \mathrm{WS}_{2}$ was estimated to be $0.13,0.62$, and 0.15 , respectively, based on the corresponding capacity (Fig. 4B, C). During potassiation, $D_{\mathrm{K} \text {-ion }}$ was estimated to be $4.53 \times 10^{-15} \mathrm{~cm}^{2} \mathrm{~s}^{-1}$ when $x=0.13$, and $3.64 \times 10^{-17} \mathrm{~cm}^{2} \mathrm{~s}^{-1}$ when $x=0.62$, both comparable to 

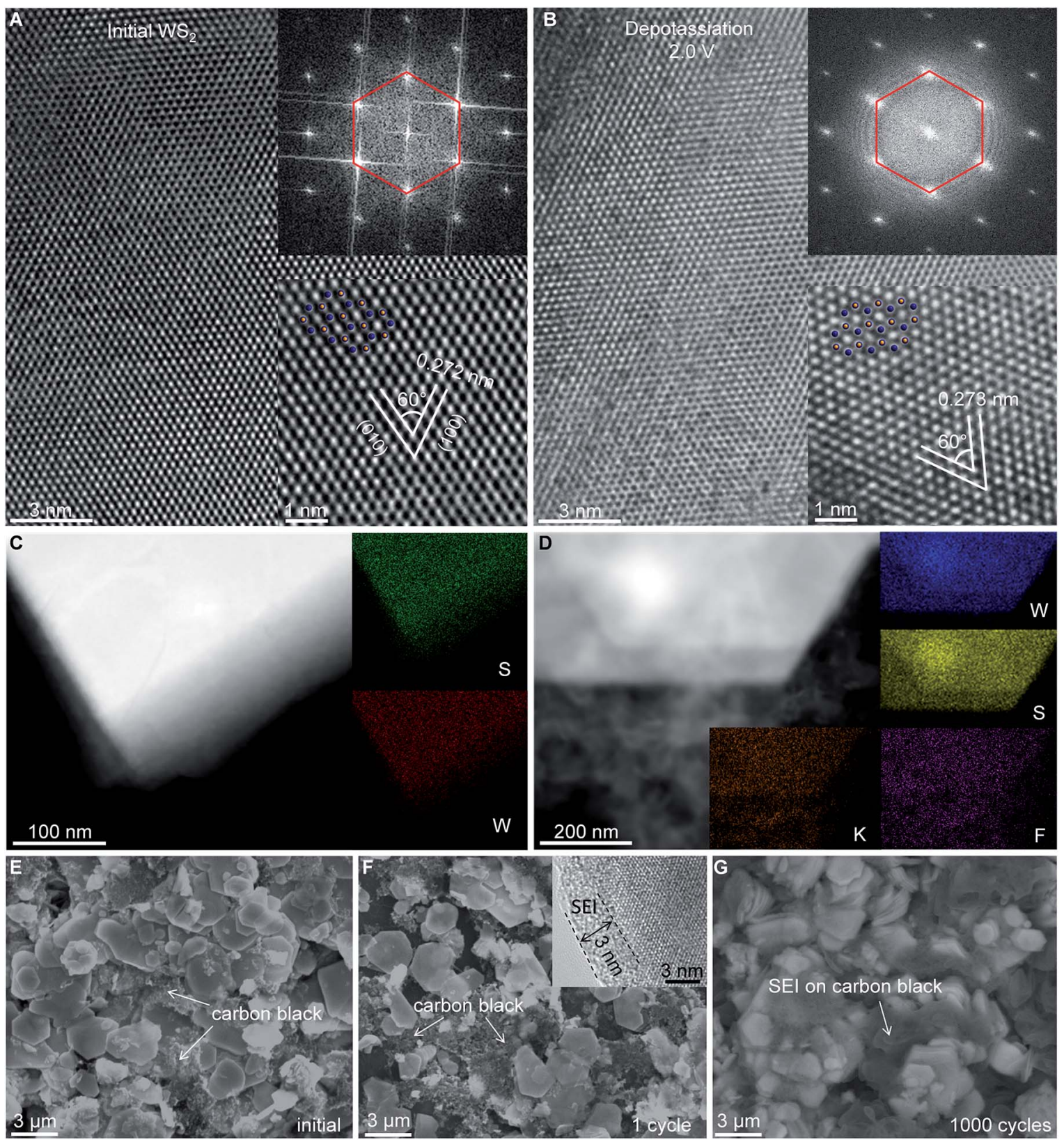

Fig. 5 Ex situ electron microscopy resolving the structural evolution of $\mathrm{WS}_{2}$. (A, B) High-resolution TEM images. The insets are the corresponding fast Fourier transformation (FFT) and HRTEM images. The blue and yellow balls represent $\mathrm{W}$ and $\mathrm{S}$ atoms, respectively. (C, D) Bright-field TEM EDS mapping of initial (C) and depotassiated (D) WS 2 . (E-G) SEM images of initial (E), single-cycled (F), and 1000-cycled (G) WS 2 anodes. The inset in (F) is an HRTEM image showing the SEI layer.

those within $\mathrm{MoS}_{2} \cdot{ }^{29} D_{\mathrm{K} \text {-ion }}$ of $2.99 \times 10^{-15} \mathrm{~cm}^{2} \mathrm{~s}^{-1}$ was deduced at $x=0.15$ during depotassiation. These values reveal that $\mathrm{K}^{+}$ diffusion was significantly restrained within the fully potassiated $\mathrm{K}_{0.62} \mathrm{WS}_{2}$. $D_{\text {K-ion }}$ was also deduced from GITT analyses using the following equation, which was first outlined by Weppner and Huggins: ${ }^{43}$

$$
D_{\text {K-ion }}=(4 / \pi \tau) \times\left[n_{\mathrm{M}} V_{\mathrm{M}} / S\right]^{2} \times\left[\Delta E_{\mathrm{s}} / \Delta E_{\mathrm{t}}\right]^{2}
$$

Herein, $\tau$ is the duration of a constant current pulse; $V_{\mathbf{M}}$ and $n_{\mathrm{M}}$ are the mole volume and mole number of active materials, respectively; $S$ is the effective contact area of active materials and electrolyte (here, the BET surface area); and $\Delta E_{\mathrm{s}}$ and $\Delta E_{\mathrm{t}}$ are the change in the steady-state voltage and overall cell voltage upon applying a current pulse in a single-step GITT experiment, respectively. As shown in Fig. 4D, the GITT study gave $D_{\text {K-ion }}$ of the order $10^{-17}$ to $10^{-16} \mathrm{~cm}^{2} \mathrm{~s}^{-1}$, similar to the ones derived from the rate-scanning $\mathrm{CV}$ results. As the intercalation reaction proceeded, $D_{\mathrm{K} \text {-ion }}$ decreased with the formation of new-phase $\mathrm{K}_{x} \mathrm{WS}_{2}$. A similar trend was observed during the reverse-phase transformation from $\mathrm{K}_{x} \mathrm{WS}_{2}$ to $\mathrm{WS}_{2}$. This phenomenon indicated that the diffusion of K-ions became more difficult during phase transitions, which is consistent with previous 

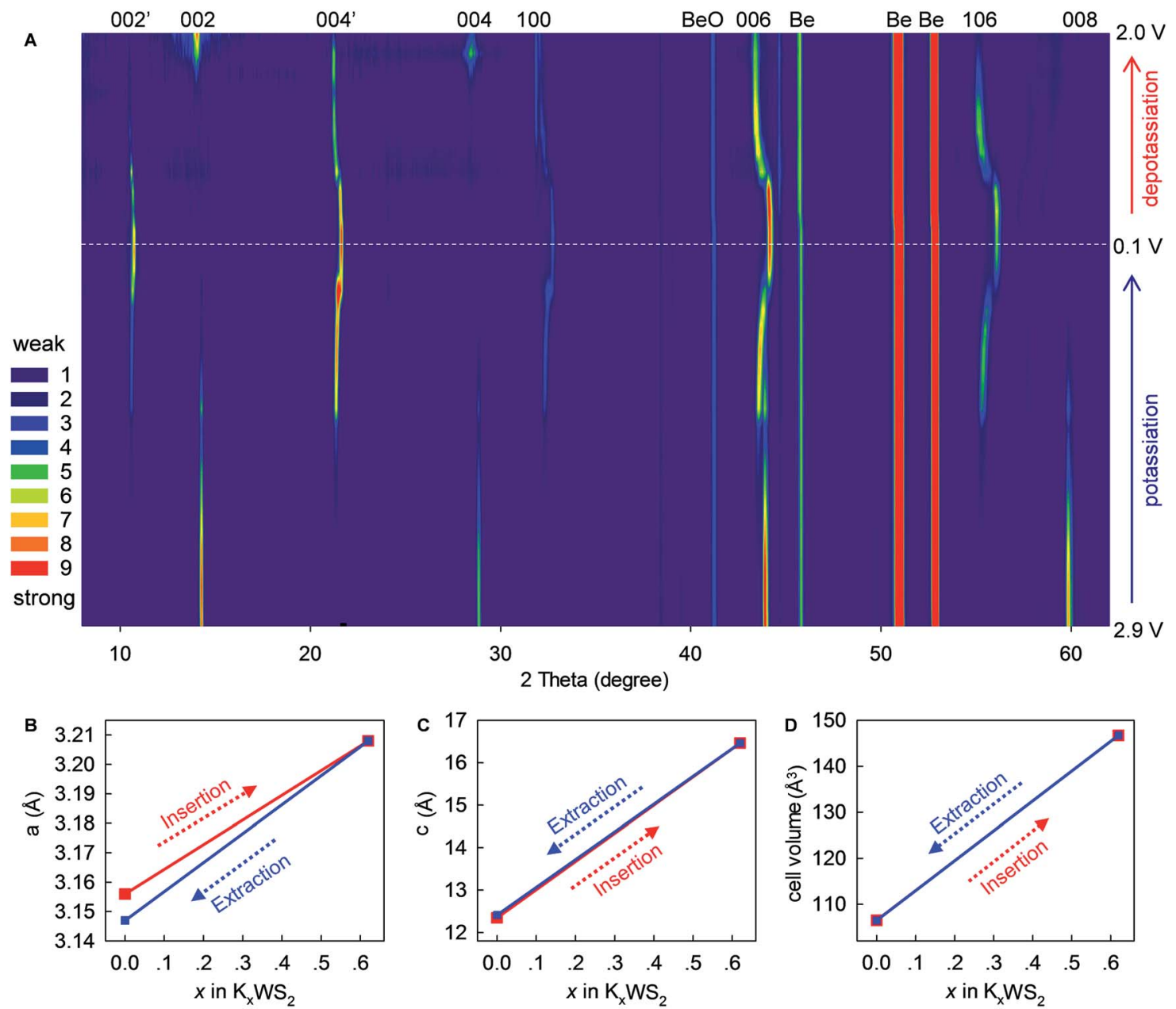

E
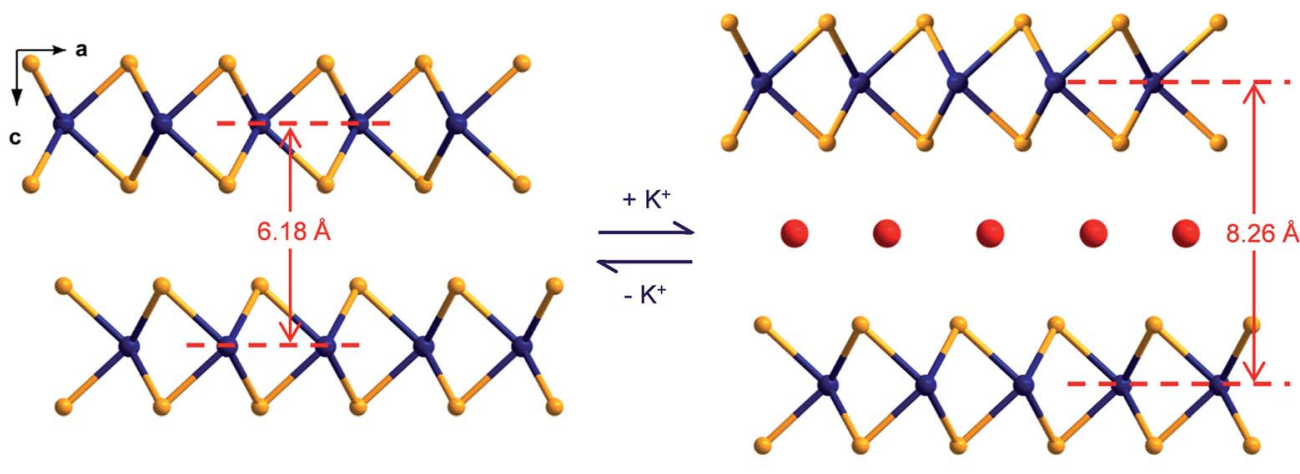

- $w$

$\mathrm{s}$

Fig. 6 Mechanistic studies of $\mathrm{K}^{+}$(de)intercalation in $\mathrm{WS}_{2}$. (A) In situ XRD patterns collected during the first (de)potassiation cycle. (B-D) Evolution in lattice constants of $\mathrm{WS}_{2}$ upon cycling. The values derived from Rietveld refinements. (E) Structural evolution of $\mathrm{WS}_{2}$ upon $\mathrm{K}^{+}$(de)intercalation (schematic).

observations. ${ }^{15}$ We speculated that the variation of $\mathrm{K}^{+}$number in the $\mathrm{WS}_{2}$ host induces a change of $\mathrm{K}^{+}-\mathrm{K}^{+}$and $\mathrm{K}^{+}-\mathrm{WS}_{2}$ interactions and, consequently, the change of $D_{\mathrm{K} \text {-ion. }}$. The obtained $D_{\text {K-ion }}$ was lower than those for $\mathrm{Li}^{+} / \mathrm{Na}^{+}$, which could be attributed to the larger size of $\mathrm{K}^{+}\left(81.6 \%\right.$ larger than that of $\left.\mathrm{Li}^{+}\right) .^{5}$ Nevertheless, the benefits from a short diffusion pathway of $\sim 0.5-1.5 \mu \mathrm{m}$ (half of the lateral size of $\mathrm{WS}_{2}$ ) and high rate capability remained achievable, as demonstrated above.
The rate capability and small electrode/electrolyte contact resistance $R_{\mathrm{f}}$ indicated that the SEI layer formed on the $\mathrm{WS}_{2}$ surface was thin, whereas the excellent electrochemical cyclability suggested the high structural stability of $\mathrm{WS}_{2}$ upon repeat $\mathrm{K}^{+}$(de)insertion. To confirm these hypotheses, ex situ electron microscopy was done. High-resolution (HR)TEM showed that the microstructure and hexagonal crystal structure of $\mathrm{WS}_{2}$ was well preserved even upon deep $\mathrm{K}^{+}$insertion/extraction (Fig. 5A, 
A

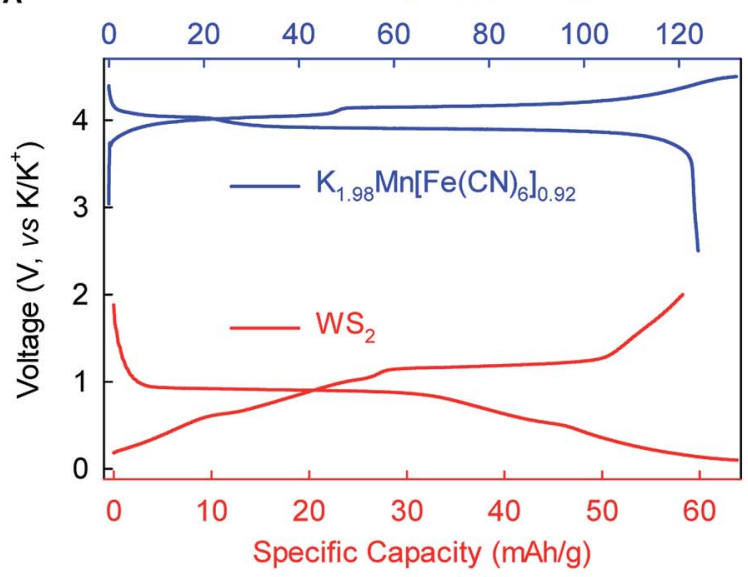

B
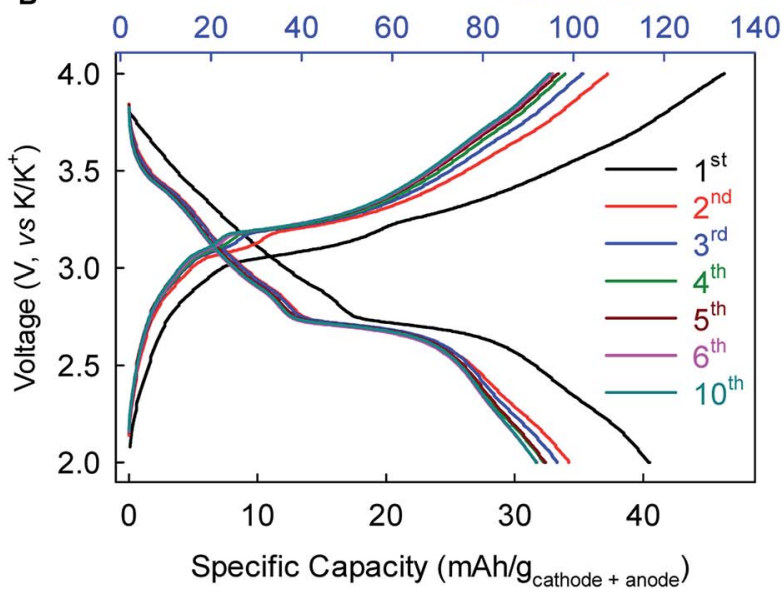

Fig. $7(+) K_{1.98} \mathrm{Mn}\left[\mathrm{Fe}(\mathrm{CN})_{6}\right]_{0.92} \| \mathrm{WS}_{2}(-)$ full-cell $\mathrm{K}$-ion batteries. (A) Voltage profiles of $\mathrm{K}_{1.98} \mathrm{Mn}\left[\mathrm{Fe}(\mathrm{CN})_{6}\right]_{0.92}$ cathode and $\mathrm{WS}_{2}$ anode at $10 \mathrm{~mA} \mathrm{~g}^{-1}$. (B) Electrochemical performance of the full-cell battery at $10 \mathrm{~mA} \mathrm{~g}^{-1}$. The mass ratio of cathode : anode is $1.7: 1$.

B and S7, ESI $\$$ ). Bright-field TEM energy-dispersive spectroscopy (EDS) mapping revealed uniform distributions of $\mathrm{W}$ and $\mathrm{S}$ elements (Fig. 5C, D), whereas a uniform spread of $\mathrm{K}$ and $\mathrm{F}$ elements on depotassiated $\mathrm{WS}_{2}$ indicated the formation of a SEI layer of thickness $\sim 3 \mathrm{~nm}$ was confirmed by HRTEM (Fig. $5 \mathrm{~F}$ and S7, ESI $\$$. Ex situ SEM presented a thick SEI layer on carbon black after 1000 cycles, making the carbon black barely visible. Conversely, much less SEI formation was observed on $\mathrm{WS}_{2}$, the morphology of which was distinctly recognizable (Fig. 5G). This observation consisted of a high average CE of $99.90 \%$, and again confirmed the structural stability of $\mathrm{WS}_{2}$ upon repeated cycling.

To provide in-depth understanding of the structural stability and mechanistic insights to this $\mathrm{K}^{+}$-(de)intercalation chemistry, in situ XRD and corresponding Rietveld refinement were done. As the $\mathrm{K}^{+}$-intercalation continued (Fig. 6A and S8, ESI+), the predominant $(002)$ Bragg peak $\left(2 \theta=14.34^{\circ}\right)$ became gradually weaker and disappeared completely at $0.1 \mathrm{~V}$. Meanwhile, a new peak named $\left(002^{\prime}\right)$ appeared at $10.69^{\circ}$ upon potassiation to $\sim 0.85 \mathrm{~V}$, and its intensity increased progressively until the completion of intercalation. Conversely, during deintercalation, the (002) peak reappeared at $14.34^{\circ}$ accompanying by the degradation and disappearance of the new $\left(002^{\prime}\right)$ peak, which suggested high reversibility of this new $\mathrm{K}^{+}$-intercalation electrochemistry. The same trend was observed for Bragg peak (004), which shifted from $28.88^{\circ}$ to $21.33^{\circ}$ upon $\mathrm{K}^{+}$-intercalation. These peak shifts indicated increases of indice spacing $d_{002}$ from 6.185 to $8.266 \AA$ and $d_{004}$ from 3.091 to $4.166 \AA$, which corresponded to $33.65 \%$ and $34.78 \%$ expansion, respectively. In contrast to the peak offset to a small angle, the Bragg peak (006) shifted slightly from $43.94^{\circ}(d=2.061 \AA)$ to $44.12^{\circ}(d=2.053 \AA)$ upon $\mathrm{K}^{+}$-intercalation and eventually to $43.40^{\circ}(d=2.085 \AA)$ upon $\mathrm{K}^{+}$-extraction. A similar changing tendency of peak offset was observed for (100) and (106) reflections, which were originally absent and first appeared at $32.31^{\circ}$ and $55.35^{\circ}$ upon potassiation to 0.8 and $0.75 \mathrm{~V}$, respectively. Differing from all above-mentioned Bragg peaks, the $(008)$ reflection $\left(2 \theta=59.8^{\circ}\right)$ faded out gradually during potassiation and no longer reappeared upon further $\mathrm{K}^{+}$-intercalation or extraction.

Rietveld refinements revealed evolution of the lattice parameters of $\mathrm{WS}_{2}$ (Fig. 6B-E and S9-11, ESI ). The lattice constants $a$ and $b(a=b=3.156 \AA)$ increased to $3.208 \AA$ upon intercalation of $0.62 \mathrm{~K}^{+}\left(\mathrm{K}_{0.62} \mathrm{WS}_{2}\right)$, which corresponded to a negligible lattice expansion of $1.65 \%$. In sharp contrast, the constant $c$ showed an increase of $33.38 \%$ (from 12.344 to 16.464 $\AA$ ) upon transforming to $\mathrm{K}_{0.62} \mathrm{WS}_{2}$, which is consistent with the evolution of indice spacing $d_{002}$ (from 6.185 to $8.266 \AA$ ) predicted based on the Bragg-peak position. Overall, the cell volume evolved from 106.478 to $146.735 \AA^{3}$ with a relatively small expansion of $37.81 \%$, which is approximately one-half that of graphite and favors high electrochemical cyclability. The $\mathrm{K}^{+}$-intercalated phase $\mathrm{K}_{0.62} \mathrm{WS}_{2}$ maintained a hexagonal structure with a space group $P \overline{6} \mathrm{~m} 2$, and staging behavior was not observed during $\mathrm{K}^{+}$-intercalation, which is similar to the observation in $\mathrm{MoS}_{2}$ but distinct to graphite. ${ }^{9,29}$ In addition, an intermediate phase was not observed during $\mathrm{K}^{+}$-intercalation, which differs from $\mathrm{K}^{+}$-intercalated $\mathrm{MoS}_{2}$, which exhibits an intermediate phase having a similar layered structure to $\mathrm{K}_{0.4} \mathrm{MoS}_{2} \cdot{ }^{29}$ Upon $\mathrm{K}^{+}$-extraction, constants $a, c$ and the cell volume shrank to $3.147 \AA$, $12.412 \AA$, and $106.455 \AA^{3}$, respectively, all of which were almost identical to the originals. Also, the $\mathrm{K}^{+}$-extracted $\mathrm{WS}_{2}$ transformed back to a hexagonal $P 6_{3} / \mathrm{mmc}$ structure. The observed evolution and restitution of lattice parameters and crystal structure demonstrated the reaction mechanism and high reversibility of $\mathrm{K}^{+}$(de)intercalation in layered $\mathrm{WS}_{2}$ which should be directly responsible for its high structural stability, long-term cyclability, rate-capability, and Coulombic efficiency.

As a proof-of-concept, we further fabricated full-cell batteries comprising a cathode of the Prussian Blue analog $\mathrm{K}_{1.98} \mathrm{Mn}$ $\left[\mathrm{Fe}(\mathrm{CN})_{6}\right]_{0.92}$ (ref. 10) and the $\mathrm{WS}_{2}$ anode. The full cells (Fig. 7) could deliver an average discharge voltage of $\sim 2.9 \mathrm{~V}$, an initial discharge capacity of $\sim 40 \mathrm{~mA} \mathrm{~h} \mathrm{~g}{ }^{-1}$ and energy density of $\sim 115 \mathrm{~W} \mathrm{~h} \mathrm{~kg}^{-1}$ based on the total mass of the cathode and anode. The capacity and energy density stabilized gradually to $32 \mathrm{~mA} \mathrm{~h} \mathrm{~g}{ }^{-1}$ and $92 \mathrm{~W} \mathrm{~h} \mathrm{~kg}^{-1}$, respectively, after five cycles. 
These prototype full-cell batteries suggest promising applications of the $\mathrm{WS}_{2}$ anode in practical PIBs.

\section{Conclusions}

We demonstrated that layered $\mathrm{WS}_{2}$ could be utilized as a $\mathrm{K}^{+}$intercalation host and store $0.62 \mathrm{~K}^{+}$per formula unit with welldefined voltage plateaus at an intrinsically safe average operation potential of $0.72 \mathrm{~V}$ (versus $\mathrm{K} / \mathrm{K}^{+}$). Mechanistic analyses confirmed the underlying intercalation mechanism and high reversibility of this battery chemistry, which accounted for its ultrahigh structural stability, electrochemical cyclability (96.3\% capacity retention over 1000 cycles) and an extraordinary average Coulombic efficiency (99.90\%). Our results reveal the promising prospect of this new $\mathrm{K}^{+}$-intercalation electrochemistry, and may shed light on PIB development for large-scale energy-storage applications.

\section{Conflicts of interest}

The authors declare no competing financial interest.

\section{Acknowledgements}

This work was financially supported by the National Natural Science Foundation of China $(21771180,51702318)$ and Natural Science Foundation of Fujian Province (2018J01031).

\section{Notes and references}

1 J. M. Tarascon and M. Armand, Nature, 2001, 414, 359-367.

2 J. B. Goodenough and Y. Kim, Chem. Mater., 2010, 22, 587603.

3 B. Dunn, H. Kamath and J. M. Tarascon, Science, 2011, 334, 928-935.

4 Y. Wang, R. Chen, T. Chen, H. Lv, G. Zhu, L. Ma, C. Wang, Z. Jin and J. Liu, Energy Storage Mater, 2016, 4, 103-129.

5 X. Wu, D. P. Leonard and X. Ji, Chem. Mater., 2017, 29, 50315042 .

6 T. Koketsu, J. Ma, B. J. Morgan, M. Body, C. Legein, W. Dachraoui, M. Giannini, A. Demortiere, M. Salanne, F. Dardoize, H. Groult, O. J. Borkiewicz, K. Chapman, P. Strasser and D. Dambournet, Nat. Mater., 2017, 16, 1142-1148.

7 S. Chen, C. Wu, L. Shen, C. Zhu, Y. Huang, K. Xi, J. Maier and Y. Yu, Adv. Mater., 2017, 29, 1700431.

8 A. Eftekhari, J. Power Sources, 2004, 126, 221-228.

9 Z. Jian, W. Luo and X. Ji, J. Am. Chem. Soc., 2015, 137, 1156611569.

10 L. Xue, Y. Li, H. Gao, W. Zhou, X. Lu, W. Kaveevivitchai, A. Manthiram and J. B. Goodenough, J. Am. Chem. Soc., 2017, 139, 2164-2167.

11 N. Xiao, W. D. McCulloch and Y. Wu, J. Am. Chem. Soc., 2017, 139, 9475-9478.

12 J. Zhao, X. Zou, Y. Zhu, Y. Xu and C. Wang, Adv. Funct. Mater., 2016, 26, 8103-8110.
13 Q. Zhang, J. Mao, W. K. Pang, T. Zheng, V. Sencadas, Y. Chen, Y. Liu and Z. Guo, Adv. Energy Mater., 2018, 1703288.

14 X. Wang, X. Xu, C. Niu, J. Meng, M. Huang, X. Liu, Z. Liu and L. Mai, Nano Lett., 2017, 17, 544-550.

15 Z. Jian, Z. Xing, C. Bommier, Z. Li and X. Ji, Adv. Energy Mater., 2016, 6, 1501874.

16 D. Su, A. McDonagh, S. Z. Qiao and G. Wang, Adv. Mater., 2017, 29, 1604007.

17 K. Lei, F. Li, C. Mu, J. Wang, Q. Zhao, C. Chen and J. Chen, Energy Environ. Sci., 2017, 10, 552-557.

18 A. Eftekhari, Z. Jian and X. Ji, ACS Appl. Mater. Interfaces, 2017, 9, 4404-4419.

19 J. Han, Y. Niu, S. J. Bao, Y. N. Yu, S. Y. Lu and M. Xu, Chem. Commun., 2016, 2, 11661-11664.

20 H. Kim, J. C. Kim, M. Bianchini, D. H. Seo, J. RodriguezGarcia and G. Ceder, Adv. Energy Mater., 2017, 1702384.

21 K. Lei, C. Wang, L. Liu, Y. Luo, C. Mu, F. Li and J. Chen, Angew. Chem., Int. Ed., 2018, 57, 4687-4691.

22 V. Mathew, S. Kim, J. Kang, J. Gim, J. Song, J. P. Baboo, W. Park, D. Ahn, J. Han, L. Gu, Y. Wang, Y. S. Hu, Y. K. Sun and J. Kim, NPG Asia Mater., 2014, 6, e138.

23 W. Luo, J. Wan, B. Ozdemir, W. Bao, Y. Chen, J. Dai, H. Lin, Y. Xu, F. Gu, V. Barone and L. Hu, Nano Lett., 2015, 15, 76717677.

24 H. Kim, J. C. Kim, S.-H. Bo, T. Shi, D. H. Kwon and G. Ceder, Adv. Energy Mater., 2017, 7, 1700098.

25 Z. Jian, S. Hwang, Z. Li, A. S. Hernandez, X. Wang, Z. Xing, D. Su and X. Ji, Adv. Funct. Mater., 2017, 27, 1700324.

26 K. Lei, F. Li, C. Mu, J. Wang, Q. Zhao, C. Chen and J. Chen, Energy Environ. Sci., 2017, 10, 552-557.

27 Q. Deng, J. Pei, C. Fan, J. Ma, B. Cao, C. Li, Y. Jin, L. Wang and J. Li, Nano Energy, 2017, 33, 350-355.

28 D. Er, J. Li, M. Naguib, Y. Gogotsi and V. B. Shenoy, ACS Appl. Mater. Interfaces, 2014, 6, 11173-11179.

29 X. Ren, Q. Zhao, W. D. McCulloch and Y. Wu, Nano Res., 2017, 10, 1313-1321.

30 J. Han, M. Xu, Y. Niu, G. N. Li, M. Wang, Y. Zhang, M. Jia and C. M. Li, Chem. Commun., 2016, 52, 11274-11276.

31 J. Zhou, L. Wang, M. Yang, J. Wu, F. Chen, W. Huang, N. Han, H. Ye, F. Zhao, Y. Li and Y. Li, Adv. Mater., 2017, 29, 1702061.

32 C. Yang, J. Feng, F. Lv, J. Zhou, C. Lin, K. Wang, Y. Zhang, Y. Yang, W. Wang, J. Li and S. Guo, Adv. Mater., 2018, 30, 1800036.

33 W. Wang, B. Jiang, C. Qian, F. Lv, J. Feng, J. Zhou, K. Wang, C. Yang, Y. Yang and S. Guo, Adv. Mater., 2018, 30, 1801812.

34 G. He and L. F. Nazar, ACS Energy Lett., 2017, 2, 1122-1127. 35 C. Zhang, Y. Xu, M. Zhou, L. Liang, H. Dong, M. Wu, Y. Yang and Y. Lei, Adv. Funct. Mater., 2017, 27, 1604307.

36 R. Zhang, J. Bao, Y. Wang and C. F. Sun, Chem. Sci., 2018, 9, 6193-6198.

37 B. Tian, W. Tang, K. Leng, Z. Chen, S. J. R. Tan, C. Peng, G. H. Ning, W. Fu, C. Su, G. W. Zheng and K. P. Loh, ACS Energy Lett., 2017, 2, 1835-1840. 
38 L. Wang, J. Zou, S. Chen, G. Zhou, J. Bai, P. Gao, Y. Wang, X. Yu, J. Li, Y.-S. Hu and H. Li, Energy Storage Mater., 2018, 12, 216-222.

39 Y. Wang, D. Kong, W. Shi, B. Liu, G. J. Sim, Q. Ge and H. Y. Yang, Adv. Energy Mater., 2016, 6, 1601057.

40 K. Shiva, H. S. S. R. Matte, H. B. Rajendra, A. J. Bhattacharyya and C. N. R. Rao, Nano Energy, 2013, 2, 787-793.
41 X. Xu, W. Liu, Y. Kim and J. Cho, Nano Today, 2014, 9, 604630.

42 D. Y. W. Yu, C. Fietzek, W. Weydanz, K. Donoue, T. Inoue, H. Kurokawa and S. Fujitani, J. Electrochem. Soc., 2007, 154, A253-A257.

43 W. Weppner and R. A. Huggins, J. Electrochem. Soc., 1977, 12, 1569-1578. 